\title{
Mitgliederversammlung des Deutschen Frauenrates
}

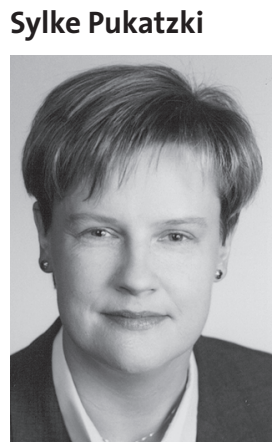

Delegierte des djb beim Deutschen Frauenrat; Rechtsanwältin, Hamburg
Wie gewohnt fand auch die Mitgliederversammlung 2007 am zweiten Novemberwochenende in Erkner bei Berlin statt. Da keine Vorstandswahlen anstanden, wurde ausschließlich Sacharbeit geleistet. Unter anderem sollte eine grundsätzliche Positionierung des Deutschen Frauenrates zum Themenschwerpunkt „Frauen und High-Tech“ sowie eine ebenso grundsätzliche Positionierung zu dem politisch vielfältig interpretierten Thema „Wahlfreiheit" beschlossen werden.

Das sehr umfangreiche inhaltliche Programm sowie die am Sonntagmittag vorzeitig erreichte Beschlussunfähigkeit der Versammlung waren der Grund, dass diese Ziele nicht im vollen Umfang erreicht werden konnten. Das ist nicht nur bedauerlich für die Sacharbeit, sondern wirft auch grundsätzliche Fragen bezüglich des Stellenwertes der Mitgliederversammlung für die einzelnen Mitgliedsverbände des Deutschen Frauenrates auf: Über den gesamten Verlauf der Tagung waren 40 der 54 Mitgliedsverbände vertreten. Beschlussfähigkeit setzt die Anwesenheit von 2/3 der Mitgliedsverbände voraus also 36 Verbände. Die Beschlussunfähigkeit ist somit schnell erreicht, weil eine Stimmenübertragung zwischen den Verbänden nicht möglich ist.

Der Vorstand ist aufgrund dieser Erfahrung an die Verbände herangetreten, um Vorschläge für die Steigerung der Attraktivität der Versammlung einzuholen. Es bleibt zu hoffen, dass dieses Verfahren positive Ergebnisse bringt. Der djb sowie auch andere Mitgliedsverbände haben in der Vergangenheit einige Vorschläge in Form von Anträgen eingebracht, die bisher keine Mehrheiten gefunden haben. Dem Vorstand des Deutschen Frauenrates

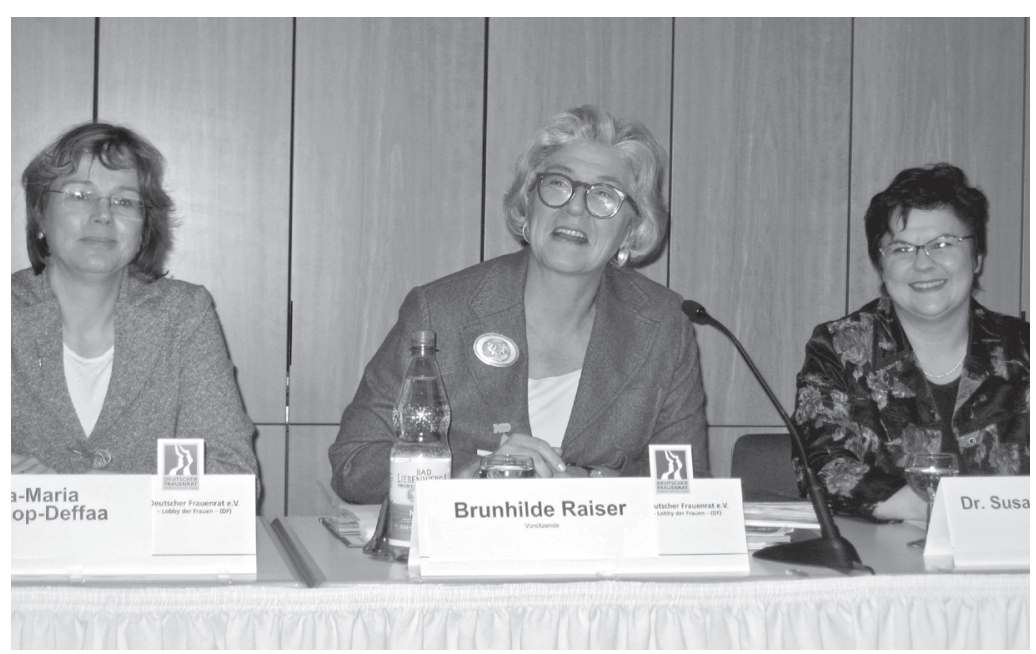

ist es wichtig, mehr in den Dialog mit den Mitgliedsverbänden einzutreten, um so auch zukünftig gute Beratungsergebnisse im Rahmen der Mitgliederversammlung zu erzielen.

Im Zusammenhang mit der Erörterung komplexer und emotional stark besetzter Themen ist festzustellen, dass aufgrund der sehr unterschiedlichen Positionen der einzelnen Verbände es sich schwierig gestaltet, diese im Rahmen der Mitgliederversammlung abschließend zu diskutieren. $\mathrm{Zu}$ diesen Themen gehört die PatientInnenverfügung. Der djb hatte einen Antrag eingebracht, welcher einen großen Teil der Verbände, die sich bisher mit dem Thema noch nicht befasst hatten, mangels einer klärenden inhaltlichen Aufbereitung etwas überforderte. Eine solche Klärung der Fakten und der Verbandspositionen soll nun im Rahmen einer Konsultation der Mitgliedsverbände zum Thema stattfinden. Insoweit war die in Abstimmung mit dem "Weibernetz“ - einem Zusammenschluss von Frauen mit Behinderung - geänderte Fassung des djb-Antrages erfolgreich.

$\mathrm{Zu}$ den komplexen und damit gut vorzubereitenden Themen gehörte auch die FGG-Reform. Das eher spröde Verfahrensrecht ist von jeher wenig attraktiv für Berufsfremde. Der Verband alleinerziehender Mütter und Väter (VAMV) hatte um Unterstützung seiner Positionen nachgesucht: Die Antragskommission sprach sich wegen der Überlänge des Antrags mit „Nichtbefassung“ aus. Ein „Rettungsversuch“, an dem ich mich beteiligte, sollte die tragenden Punkte des Positionspapiers zusammenfassen und damit den Deutschen Frauenrat handlungsfähig machen für eine Stellungnahme zum Gesetzentwurf. Leider scheiterte diese Aktion an der zwischenzeitlich eingetretenen Beschlussunfähigkeit der Versammlung.

Positiv stimmt es, dass die Dialogbereitschaft zwischen den Verbänden Veränderungsprozessen zukünftig mehr Raum geben kann.

\footnotetext{
4 Eva Maria Welskop-Deffaa (Leiterin der Abteilung Gleichstellung im BMFSFJ, Berlin), Brunhilde Raiser (1. Vorsitzende des Deutschen Frauenrates, Berlin) und Dr. Susanna Schmidt (Leiterin der Abteilung Strategien und Grundsatzfragen im BMBF, Berlin) (vInr).

Copyright: Deutscher Frauenrat.
} 